
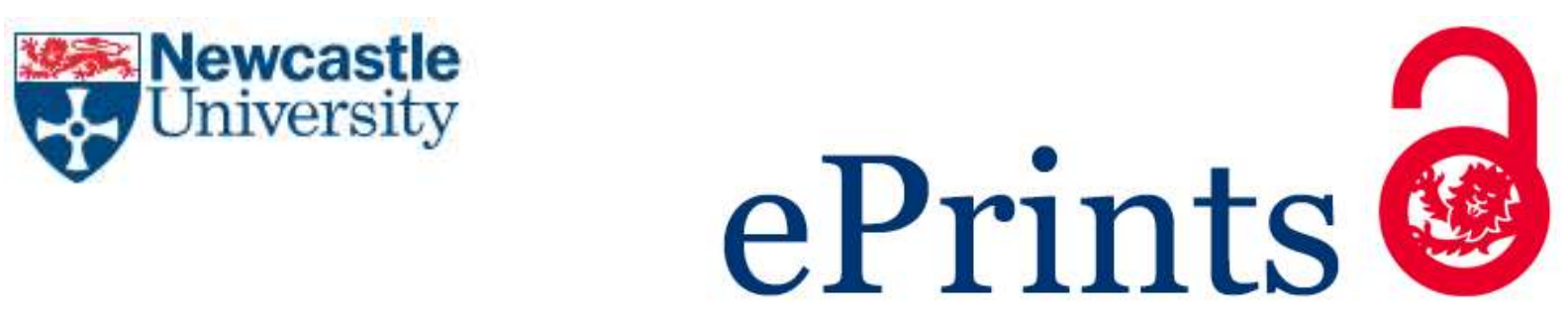

Fang YD, Lu YJ, Yu XL, Roskilly AP. Experimental study of a pneumatic engine with heat supply to improve the overall performance. Applied Thermal Engineering 2018, 134, 78-85.

\title{
Copyright:
}

(C) 2018. This manuscript version is made available under the CC-BY-NC-ND 4.0 license

DOI link to article:

https://doi.org/10.1016/i.applthermaleng.2018.01.113

Date deposited:

$13 / 02 / 2018$

Embargo release date:

31 January 2019

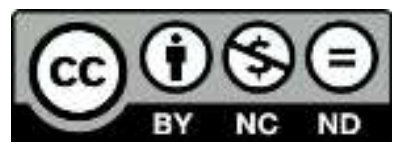

This work is licensed under a

Creative Commons Attribution-NonCommercial-NoDerivatives 4.0 International licence 


\section{Experimental study of a pneumatic engine with heat supply to improve 2 the overall performance}

3 Yidong Fang ${ }^{\mathrm{a}, \mathrm{c}}$, Yiji Lu ${ }^{\mathrm{b}, \mathrm{c}, *}$, Xiaoli Yu ${ }^{\mathrm{b}}$, Anthony Paul Roskilly ${ }^{\mathrm{b}, \mathrm{c}}$

$4 \quad{ }^{a}$ School of Energy and Power Engineering, University of Shanghai for Science and Technology, Shanghai 200093, China

$5 \quad{ }^{b}$ Department of Energy Engineering, Zhejiang University, Hangzhou 310027, China

$6 \quad{ }^{c}$ Sir Joseph Swan Centre for Energy Research, Newcastle University, Newcastle NE1 7RU, United Kingdom

\section{$7 \quad$ H I G H L I G H T S}

8 - The design of a pneumatic engine modified from diesel engine was reported

- Performance study of a pneumatic engine with and without heat supply

- Two pressure and two temperature conditions under different rotational speed

\section{Abstract}

As an environmental friendly technology, hybrid pneumatic concept regenerating the engine braking energy to boost the engine performance for better fuel economy and lower engine emissions attracts ever increasingly attentions in automotive industry. However, the pneumatic operational mode of the engine suffers from low energy efficiency, which requires more research efforts. This study presents an optimisation method for the pneumatic mode of hybrid pneumatic engine by supplying heat during the expansion process of compressed air. A pneumatic prototype engine has been designed, constructed and used to simulate the working process of the engine during pneumatic mode. Hot water has been used as the heat source to heat up

\footnotetext{
* Corresponding author. Tel.: +44 (0) 1912084827

E-mail address: yiji.lu@ncl.ac.uk; luyiji0620@gmail.com (Y.Lu);
} 
engine. The results show that the power and torque of the pneumatic prototype engine under the heat source temperate at $90{ }^{\circ} \mathrm{C}$ and $1 \mathrm{MPa}$ intake pressure are both increased. The maximum power output of the HPE obtained is around $1.5 \mathrm{~kW}$, which is $22 \%$ higher than that of the HPE without heat supply. Under the engine rotational speed at $400 \mathrm{r} / \mathrm{min}$, the torque produced from the HPE is about $29 \mathrm{~N} \cdot \mathrm{m}$, which is $7 \%$ improvement than that without heating supply. The maximum energy efficiency of the HPE can be improved from $27 \%$ to $35 \%$, when the cylinder wall is heated by $90{ }^{\circ} \mathrm{C}$ water and the intake pressure is set at $1 \mathrm{MPa}$. Moreover, the

effects of hot water temperature have also been investigated and in total twenty one testing points have been conducted under the engine intake pressure set at $1 \mathrm{MPa}$. The maximum power output from the HPE under water temperature at $70{ }^{\circ} \mathrm{C}$ and $90{ }^{\circ} \mathrm{C}$ can respectively be as high as $1.4 \mathrm{~kW}$ and $1.5 \mathrm{~kW}$, which is about $14 \%$ and $22 \%$ improvement compared with the HPE without heat supply.

Key words: Hybrid Pneumatic Engine, heat supply or recovery, pneumatic mode, performance study

\section{$31 \quad 1$ Introduction}

because the hybrid system has been proven as an effective solution to improve the overall efficiency of the

vehicle and reduce the fuel consumption [1,2]. The most well-known hybrid technology is hybrid electric (HPE), which adds an extra charging valve on the cylinder head of Internal Combustion Engine (ICE), has 
41 form of compressed air and reuses the energy during acceleration at later time $[4,5]$. Higelin et al. [6-8]

42 conducted simulation on HPE and claimed that the reduction on fuel consumption can be as high as $15 \%$

43 under New European Driving Cycle (NEDC) and even up to 31\% under optimised operational conditions.

44 Trajkovic et al. [9-13] modified a single-cylinder ICE into HPE by using pneumatic valve actuator, and conducted experiments to study its performance and efficiency. The results showed that the fuel consumption of ICE can be reduced by $30 \%$ after applying HPE, and the extra cost of HPE was claimed to be a fraction of that for an electric hybrid arrangement due to its simplicity $[9,10]$. In addition, the optimisation on valve parameters and timing was also conducted [11]. Zhao et al. [14-17] conducted numerical simulation on HPE based on a cam profile switching device. The results showed that a $6.8 \%$ reduction in fuel consumption could be achieved as a result of the application of HPE [17]. The compressed air recovered during vehicle brake was also available to provide instant boost so that a highly downsized engine could be used for further improvement in fuel economy without the loss in performance or greater emissions associated with turbo-lag. Donitz et al. [18-20] investigated the fuel consumption reduction of HPE when it is combined with engine downsizing. The results showed that a fuel consumption reduction was up to $34 \%$ for the MVEG-95 drive cycle and the turbo-lag normally associated with heavy downsizing could be overcome with HPE by using compressed air from the tank to supercharge the engine during the acceleration of the turbocharger [18-20].

57 Basbous et al. [21-24] and Ibrahim et al. [25, 26] applied HPE concept on wind-diesel generators to reduce

58 fuel consumption for electricity production in non-interconnected remote areas. Results showed that the fuel economy generated by HPE was 10\% 26\% under different wind power conditions. Wang et al. [27] conducted a simulation study on a HPE to regenerate the braking energy and urban driving-cycle simulation 
by $8 \%$. A two-stage expansion air engine, which includes one small and one large cylinder to conduct two-stage in series has been proposed and investigated by Liu et al. [28]. Results indicated the two-stage expansion air engine can generate up to $1.7 \mathrm{~kW}$ power and $12.42 \mathrm{Nm}$ torque at air pressure of 12 bar [28].

As described previously, the application of HPE enables engine to work in different modes. The waste energy is recovered from ICE and stored as compressed air in compressor mode by operating the engine as air compressor during the vehicle brake. Under conditions like vehicle start, HPE is operated in pneumatic mode and the engine works just like a pneumatic motor and the pressurised air flows into the cylinder and produces power by expansion. Some researchers reported the efficiency of the pneumatic mode of HPE is lower than $20 \%$ [29-32]. Therefore, the performance of pneumatic mode requires research efforts in order to optimise the HPE performance. However, limited study has been reported and conducted focusing on the issues mentioned above. This study aims to experimentally investigate the effects of using heat supply on the pneumatic mode of HPE in order to improve the overall efficiency and performance of the HPE. A prototype pneumatic engine with heat supply system has been designed, built and tested to study the effects of using heat supply on the performance of the HPE. The results obtained from this study can be used as a useful reference not only for

\section{2. Methodologies}

792.1 Description of the Hybrid Pneumatic Engine (HPE) 


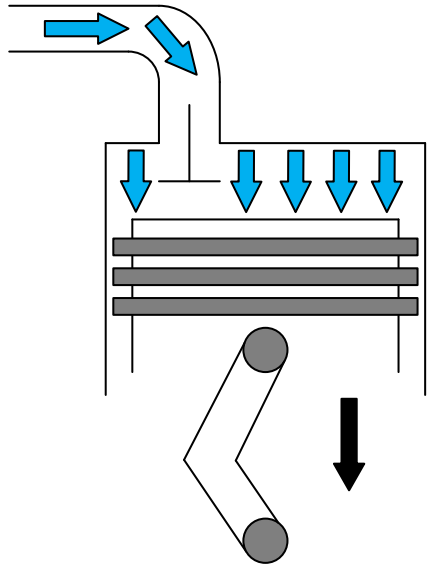

(a)

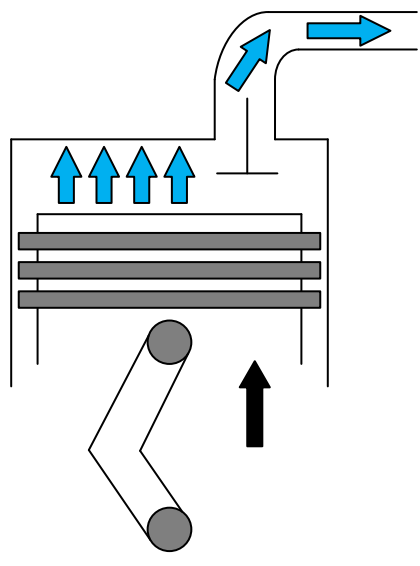

(b)

Fig. 1. Schematic diagram of the working principle of pneumatic mode (a) intake and expansion, (b) exhaust The working principle of the HPE can be described as the following modes. In the firing mode, HPE

81 works the same as a normal ICE, while brake energy is recovered and stored in forms of compressed air in the compressed air storage tank. When working in pneumatic mode, the engine works as a pneumatic motor with the fuel-injection being cut-off converting the compressed air energy into mechanical work. Fig. 1 illustrates the typical working process of the pneumatic mode of HPE. The two-stroke process is composed of intake, expansion and exhaust process. The intake valve opens when the piston moves to the Top Dead Centre (TDC) and closes at some time during the intake process. The compressed air flows from air tank to the cylinder

87 during the intake process, pushing the piston to move downwards. After the intake valve is closed, the compressed air continues to expand in the cylinder until the piston reaches the Bottom Dead Centre (BDC).

89 Then the exhaust valve opens after the expansion process and the remaining compressed air is pumped out of the cylinder by the piston. 


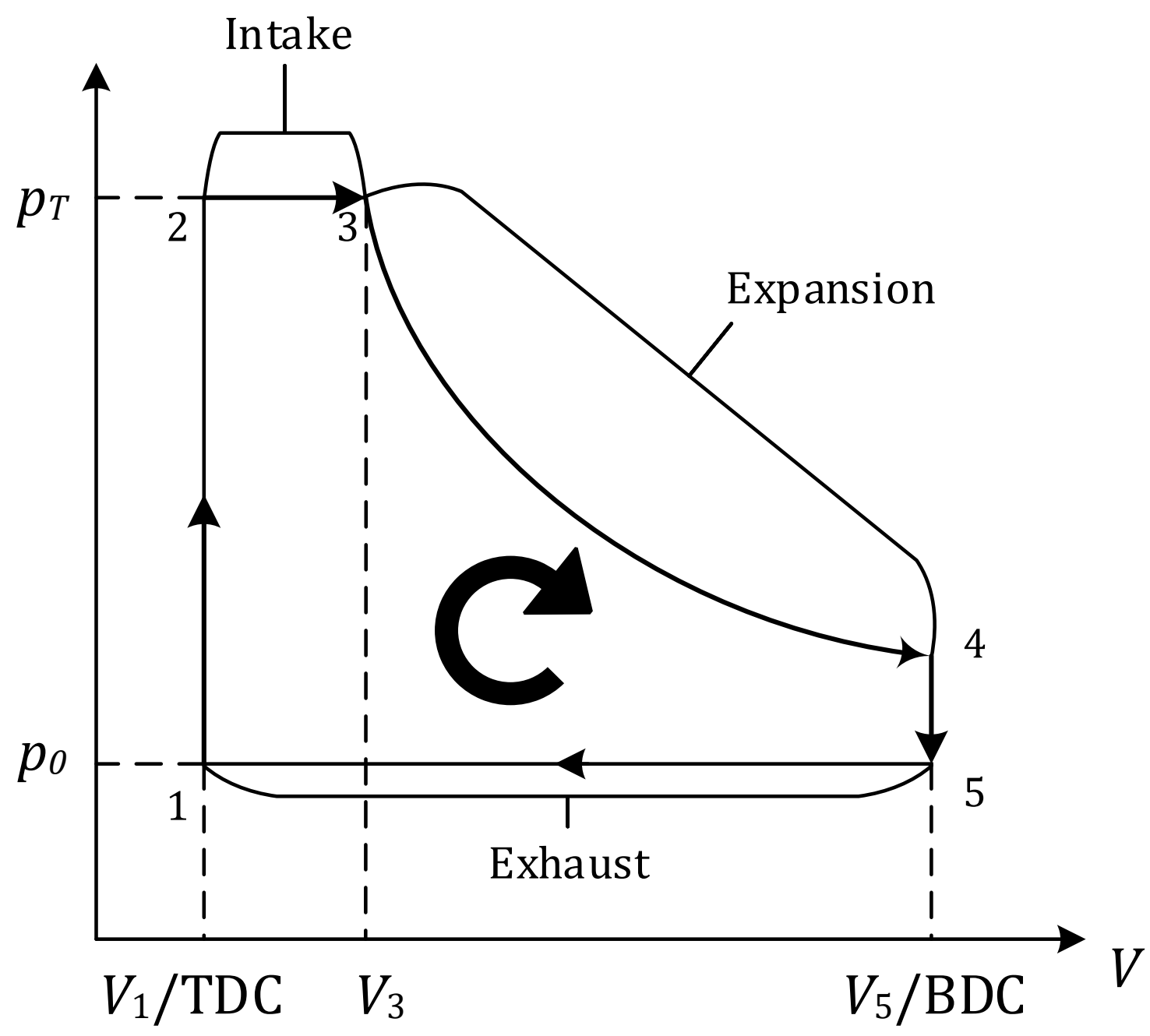

Fig. 2. $P-V$ diagram of the pneumatic mode

Fig. 2 illustrates the ideal thermodynamic cycle of the pneumatic mode of HPE. According to the above

92 description, the intake process 1-3 begins when the intake valve opens at TDC. Note that the pressure rises

93 immediately to tank pressure $p_{T}$ after the opening of intake valve, and remains constant during the intake

94 process. Therefore the intake process can be regarded as isobaric. Compressed air flows into the cylinder

95 during the intake process and pushes the piston to move downwards to produce power. The intake valve

96 closes at some time before the piston reaches BDC, thus changing the isobaric intake process into an

97 expansion process 3-4. The compressed air continues to expand until the piston reaches BDC, followed by the 
exhaust process 5-1 after the opening of the exhaust valve. Finally the compressed air is pumped out of the cylinder during the upward movement of the piston.

$$
W=W_{1-3}+W_{3-4}
$$

The efficiency of the cycle can be expressed as Eq. (2). $E$ is the total energy contained in the compressed air, which can be calculated as Eq. (3), where $m$ indicates the mass of compressed air flowing into the cylinder per cycle. It can be noted that the total energy $E$ remains constant if the pressure, temperature and the mass of compressed air are unchanged, hence the only way to achieve an efficiency improvement is to maximise the net work of the cycle.

$$
\begin{aligned}
& \eta=\frac{W_{1-3}+W_{3-4}}{E} \\
& E=m R T \ln \frac{p_{T}}{p_{0}}
\end{aligned}
$$
where $V_{1}$ is the cylinder volume when the piston is at TDC, and $V_{3}$ is the cylinder volume when the intake valve is closed. It can be noted that $W_{1-3}$ remains constant if the tank pressure and valve timing of the pneumatic mode is unchanged. Therefore, the net work of the cycle depends on the expansion work of compressed air $W_{3-4}$. 
$W_{1-3}=p_{T}\left(V_{3}-V_{1}\right)$

112 If there is no heat transfer during the expansion process, the expansion work $W_{3-4}$ can be expressed as Eq.

113 (5), where, $\kappa(=1.4)$ is the adiabatic index of compressed air, and $\varepsilon=V_{3} / V_{4}$ is the volume ratio between the

114 initial and final state of the expansion process.

$W_{3-4}=\frac{p_{T} V_{3}}{\kappa-1}\left[1-\varepsilon^{\kappa-1}\right]$

If the expansion process is isothermal, $W_{3-4}$ can be expressed as

$W_{3-4}=p_{T} V_{3} \ln \varepsilon$

Due to the heat absorption during the process, the work of isothermal expansion is larger than that of

117 adiabatic expansion if the initial state and the volume ratio is fixed. For the expansion process of the 118 pneumatic mode, the maximum and the minimum work can be achieved in the cases of isothermal and 119 adiabatic expansion, respectively. However, neither isothermal nor adiabatic process can be achieved during 120 practice, and the actual expansion of compressed air is a polytropic process distributing between isothermal 121 and adiabatic expansion. Therefore, an effective way to maximise the expansion work of compressed air is to 122 supply additional heat during the expansion, thus making the expansion process evolve towards isothermal 123 expansion, and eventually leading to an increase in the net work of the cycle.

\section{$124 \quad$ 2.2. Experimental methods}

\section{$125 \quad$ 2.2.1 Design of Pneumatic prototype engine}


As mentioned above, an increase in the work output of the pneumatic mode can be potentially achieved

127 by supplying heat to the expansion process of compressed air. In order to validate the analysis above, the 128 pneumatic mode of HPE should be realized on the test bench before designing the heat supply system. 129 However, the pneumatic mode is only activated during transient conditions such as vehicle start or engine 130 acceleration, hence it is impossible to obtain its performance properties such as power and torque under steady 131 conditions. To confront this problem, a pneumatic prototype engine is developed in this study to simulate the 132 working process of pneumatic mode of HPE.

133 The two-stroke pneumatic prototype engine is re-configured based on a single-cylinder diesel engine, as 134 shown in Fig. 3. The cylinder head of the original diesel engine has been re-designed to satisfy the demand of 135 valve timing of pneumatic mode. Fig. 4 shows the rotational valve system adopted on the pneumatic prototype 136 engine. The exhaust valve is driven by a sprocket wheel system which is connected to the crankshaft, and the 137 intake valve is connected to the exhaust valve through gear transmission. The valve timing is shown in Table 1381 along with the main specifications of the prototype, and it can be changed by adjusting the gear connection 139 between the intake and exhaust valve. The intake valve opens immediately when the piston moves to TDC, 140 and compressed air flows into the cylinder during the intake process which lasts for $72^{\circ} \mathrm{CA}$. After the intake 141 valve is closed, the compressed air in the cylinder continues to expand until the piston moves to BDC. Then 142 the exhaust valve opens and the piston moves from BDC to TDC to pump the compressed air in the cylinder during the exhaust process. 


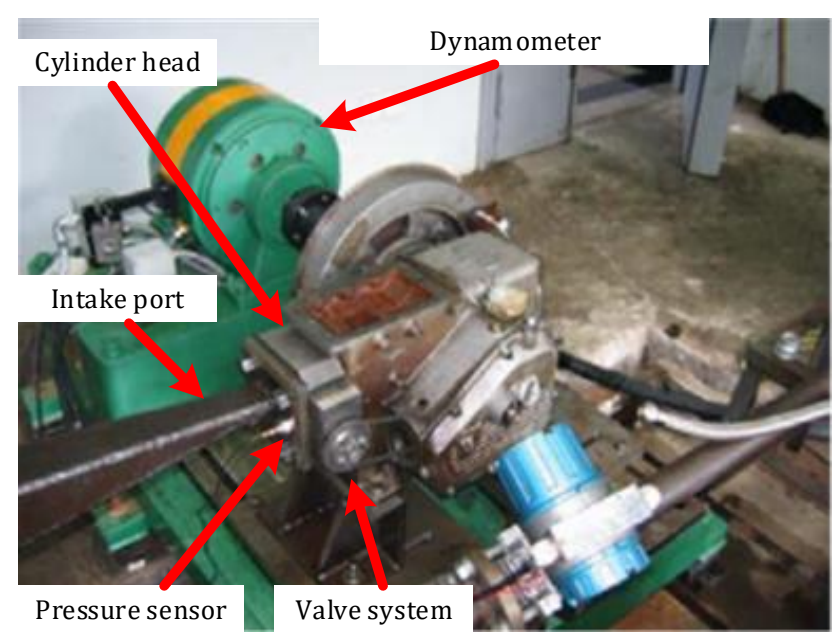

Fig. 3. Photo of the prototype pneumatic engine

\section{Table 1}

145 Specifications of the prototype pneumatic engine

\begin{tabular}{ll}
\hline Item & Value \\
\hline Bore $(\mathrm{mm})$ & 85 \\
Stroke $(\mathrm{mm})$ & 95 \\
Displacement $(\mathrm{L})$ & 0.54 \\
Intake valve open $\left({ }^{\circ} \mathrm{CA}\right.$ ATDC) & 0 (TDC) \\
Intake valve close $\left({ }^{\circ} \mathrm{CA}\right.$ ATDC) & 72 \\
Exhaust valve open $\left({ }^{\circ} \mathrm{CA}\right.$ ATDC) & 180 (BDC) \\
Exhaust valve close $\left({ }^{\circ} \mathrm{CA}\right.$ ATDC) & 360 (TDC) \\
\hline
\end{tabular}

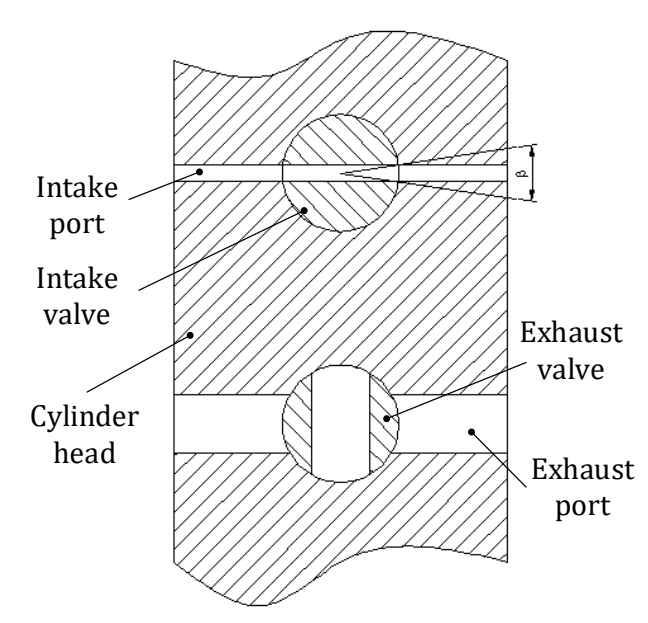

Fig. 4. Schematic of the rotational valve 
149 tank, a flowmeter, a dynamometer and sensors. During the experiment, the pneumatic prototype engine is 150 driven by the compressed air stored in the air tank with $300 \mathrm{~L}$ in volume and $2.5 \mathrm{MPa}$ in maximum pressure.

151 A pressure regulator is placed at the outlet of the tank to adjust the intake pressure of the pneumatic prototype 152 engine. The intake pressure is always lower than the tank pressure so that a steady flow of compressed air can 153 be ensured. The power and torque of pneumatic engine are monitored by the dynamometer (DW-20, Hongxin 154 Inc., China), and the compressed air flow rate is monitored by the flowmeter (HQ-980, Huaqiang Inc., China). 155 The intake pressure and temperature of pneumatic prototype engine are measured by a pressure sensor 156 (PT-110, Qizheng Inc., China) and a thermistor, respectively. In addition, the cylinder pressure of pneumatic 157 prototype engine is measured by a transient pressure sensor (Type 6013C, Kistler Inc., Germany).

The heat supply module is used to provide heat to the expansion of compressed air during working process of the pneumatic prototype engine. It should be noted that the water jacket of the diesel engine is maintain unchanged during its modification to the pneumatic prototype engine. During the experiment, an electric heater with a maximum power of $2 \mathrm{kWe}$ is placed in a water tank to heat the water. Then the hot water 162 is guided out by a pump to flow through the water jacket, thus providing heat to compressed air by raising the 163 cylinder wall temperature. After that, the water flows back to the tank, forming a complete circuit. The power 164 of the heater is controlled so that the water temperature at the outlet of the tank is maintained constant during 165 the experiment. The power of the electric heater was not considered during the calculation of the efficiency 166 since its function was to simulate the waste heat source during the practical operation of HPE. The 167 temperature difference of the water is monitored by thermistors, which are place at both inlet and outlet of the 168 water jacket of the pneumatic prototype engine. An electromagnetic flowmeter (LDCK-10, Shanghai 


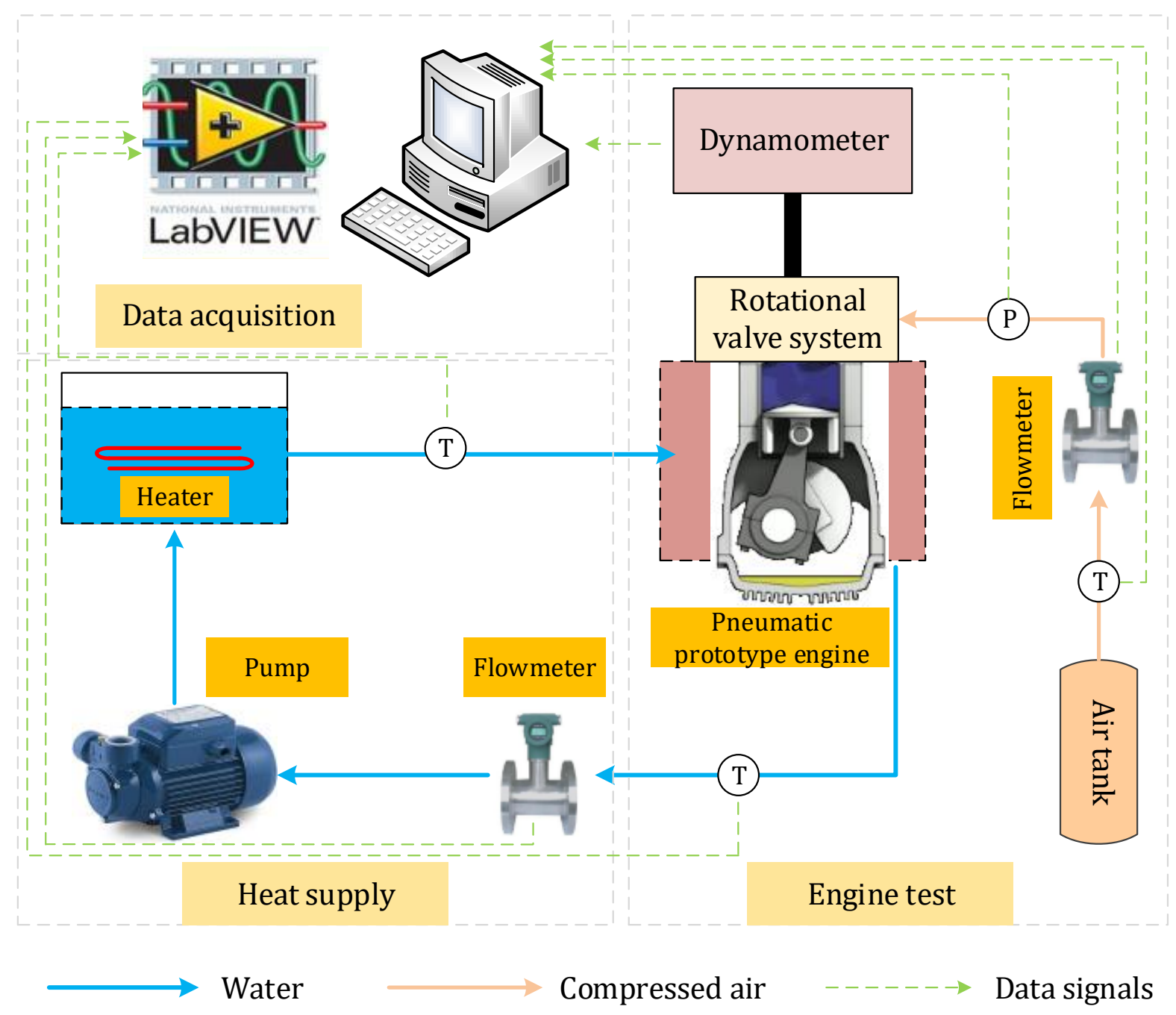

Fig. 5. Schematic of the experimental system

174 USA). Different input devices are selected to collect the signals of the sensors, and all signals are eventually

175 processed by a data acquisition program designed based on Labview. The specifications of the sensors are

176 listed in Table 2, and it should be noted that all sensors were calibrated before the experiment. 
178 Specifications of the data acquisition equipment

\begin{tabular}{|c|c|c|c|c|}
\hline & Power Supply & Output & Range & Accuracy \\
\hline Dynamometer DW-20 & $220 \mathrm{~V} \mathrm{AC}$ & Digital display & $0 \sim 20 \mathrm{~kW}$ & $\pm 0.2 \% \mathrm{FS}$ \\
\hline Flowmeter LDCK-10 & $220 \mathrm{~V}$ AC & Digital display & $0 \sim 18 \mathrm{~m}^{3} / \mathrm{h}$ & $\pm 0.5 \% \mathrm{FS}$ \\
\hline Flowmeter HQ-980 & $24 \mathrm{~V} \mathrm{DC}$ & Current, 4 20 mA & $0 \sim 150 \mathrm{~kg} / \mathrm{h}$ & $\pm 1 \% \mathrm{FS}$ \\
\hline Thermistors & $24 \mathrm{~V} \mathrm{DC}$ & Voltage, $0 \sim 5 \mathrm{~V}$ & $0 \sim 100^{\circ} \mathrm{C}$ & $\pm 0.5 \% \mathrm{FS}$ \\
\hline Pressure sensor $6013 \mathrm{C}$ & $24 \mathrm{~V} \mathrm{DC}$ & Voltage, $0 \sim 10 \mathrm{~V}$ & $0 \sim 15 \mathrm{MPa}$ & $\pm 0.5 \% \mathrm{FS}$ \\
\hline Pressure sensor PT-110 & $24 \mathrm{~V} \mathrm{DC}$ & Voltage, $0 \sim 5 \mathrm{~V}$ & $0 \sim 1.6 \mathrm{MPa}$ & $\pm 0.5 \% \mathrm{FS}$ \\
\hline
\end{tabular}

\section{$179 \quad$ 2.2.3 Experiment conditions}

180 The pneumatic prototype engine is operated within the speed range of $400 \sim 1000 \mathrm{r} / \mathrm{min}$ to study the 181 performance of the pneumatic mode of HPE. As stated in the manuscript Section 2.2.2, the prototype 182 pneumatic engine has been modified from a diesel engine. The two selected pressure conditions are the typical 183 working conditions of the prototype pneumatic engine. When the prototype pneumatic engine is running lower 184 than 0.6 MPa supplied pressure, the engine cannot be started smoothly and no effective data can be obtained 185 in the experimental tests. The other testing pressure is $1 \mathrm{MPa}$, which is selected to prevent the exploration of 186 the high pressure air tank when the prototype engine works under steady state for a period of time. 
On the other hand, the structure of water jacket of the diesel engine has not been changed. The coolant temperature from a conventional ICE varies from 70 to $90{ }^{\circ} \mathrm{C}[33,34]$. The two selected heated temperature conditions 70 and $90{ }^{\circ} \mathrm{C}$ can be used to provide as the reference for the development of Hybrid Pneumatic

Engine and validate the analysis conducted in the Section 2.1, which shown the expansion process of compressed air is adiabatic if there is no heat supply during the expansion and with the increase of the heat supply, the expansion process will develop towards isothermal, which will lead to an improvement on the performance of the pneumatic mode. Therefore the selected temperature $70{ }^{\circ} \mathrm{C}$ is used to prove the concept of adding heat into Pneumatic Engine to improve the overall system efficiency. And the selected temperature 90

${ }^{\circ} \mathrm{C}$ is to prove that the expansion process can be developed towards isothermal process with the increase of heat supply as described previously.

\section{Results and discussion}

\subsection{Effects of heat supply}

Fig. 6 shows the cylinder pressure of pneumatic prototype engine acquired under the speed of $600 \mathrm{r} / \mathrm{min}$

and the intake pressure of $1 \mathrm{MPa}$. Case A indicates that the engine works when the electric heater is switched off, while case B refers to the condition that the water is heated to $90{ }^{\circ} \mathrm{C}$ and used to raise the temperature of the cylinder wall of the engine. It can be noted that the cylinder pressure is higher when the water is used to heat the cylinder wall, especially at the expansion stage of compressed air. The peak cylinder pressure of case $\mathrm{B}$ is above $0.8 \mathrm{MPa}$, which is approximately $10 \%$ higher than that of case $\mathrm{A}$, when the cylinder wall is not heated by the water. In addition, the area surrounded by the $p$ - $V$ curve is also larger under case $\mathrm{B}$ when the 
207 cylinder wall temperature. This phenomenon can be explained by the enhancement of heat absorption of 208 compressed air, hence the expansion process of the pneumatic mode is optimised and develops towards 209 isothermal due to the additional heat supply under higher cylinder wall temperature. It can be concluded that 210 the working process of the pneumatic mode of HPE can be improved when the cylinder wall temperature is 211 raised, while the waste heat of ICE could serve as an ideal heat source and be used to increase the mechanical 212 work output during the pneumatic mode.

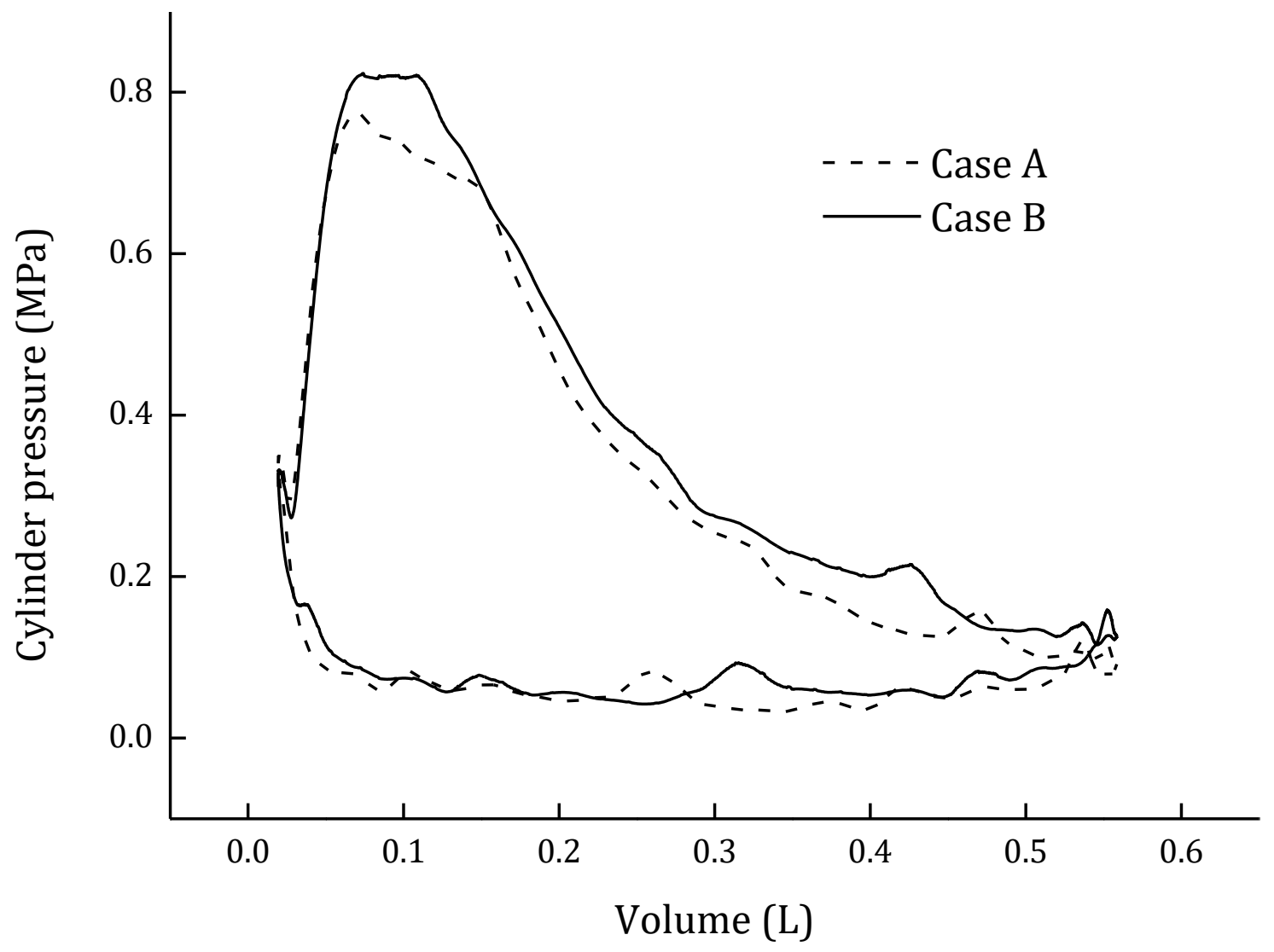

Fig. 6. Cylinder pressure of pneumatic prototype engine

214 Fig. 8, respectively. Similarly, the legend Case A in the figures indicate the condition that the engine works 215 without the cylinder wall being heated by the water, while Case B refers to the condition that the water 
216 (heated to $90{ }^{\circ} \mathrm{C}$ ) is used to heat the cylinder wall. Note that the power of the pneumatic prototype engine first 217 increases then drops with the speed, while the torque of the engine decreases monotonously with the speed.

218 The reason can be explained by the fact that the mass of compressed air in the cylinder decreases with the rise 219 of the engine speed due to the reduction of intake valve opening period.

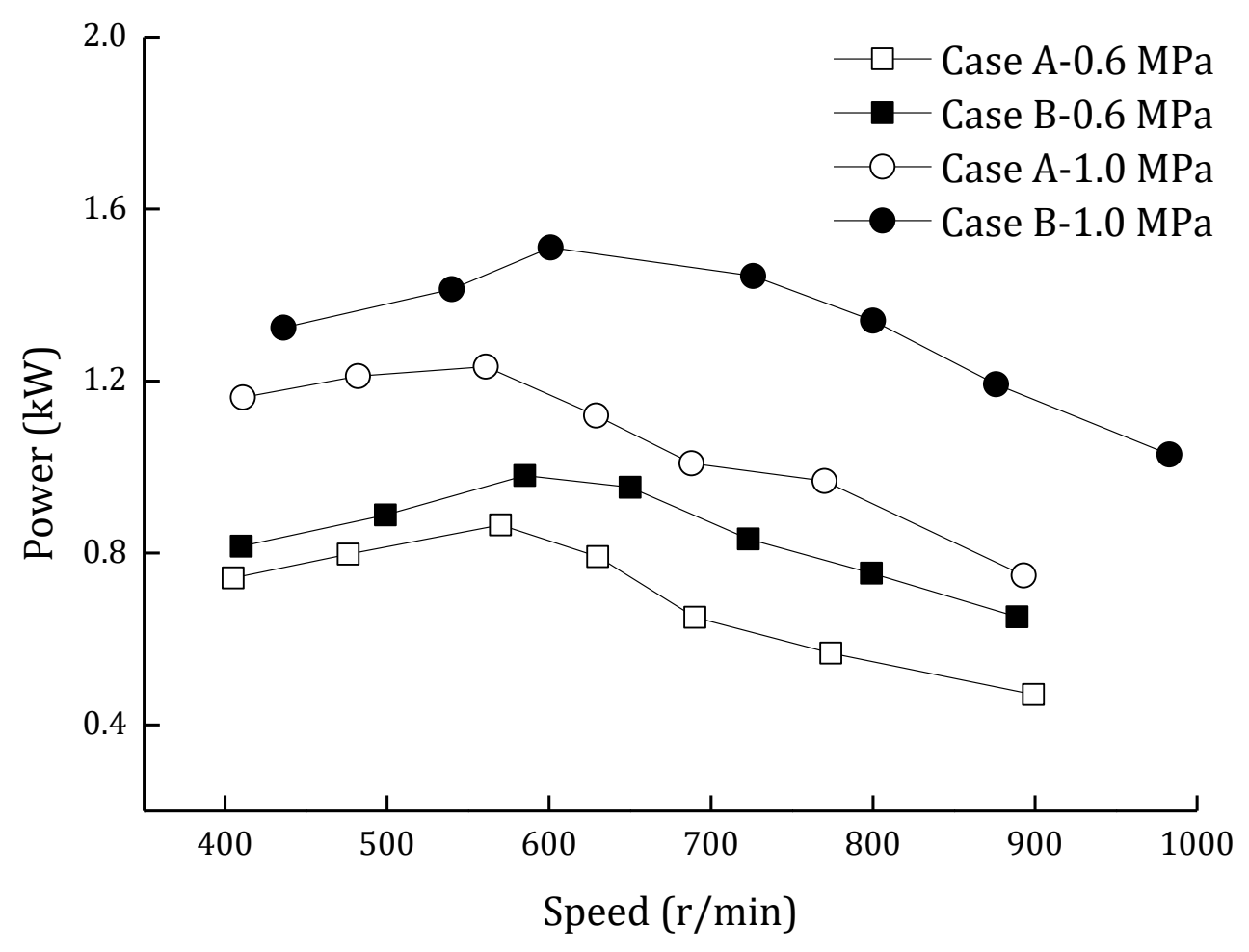

Fig. 7. Pneumatic prototype engine power vs. engine speed at $p_{\mathrm{i}}=0.6 \mathrm{MPa}, 1.0 \mathrm{MPa}$ 


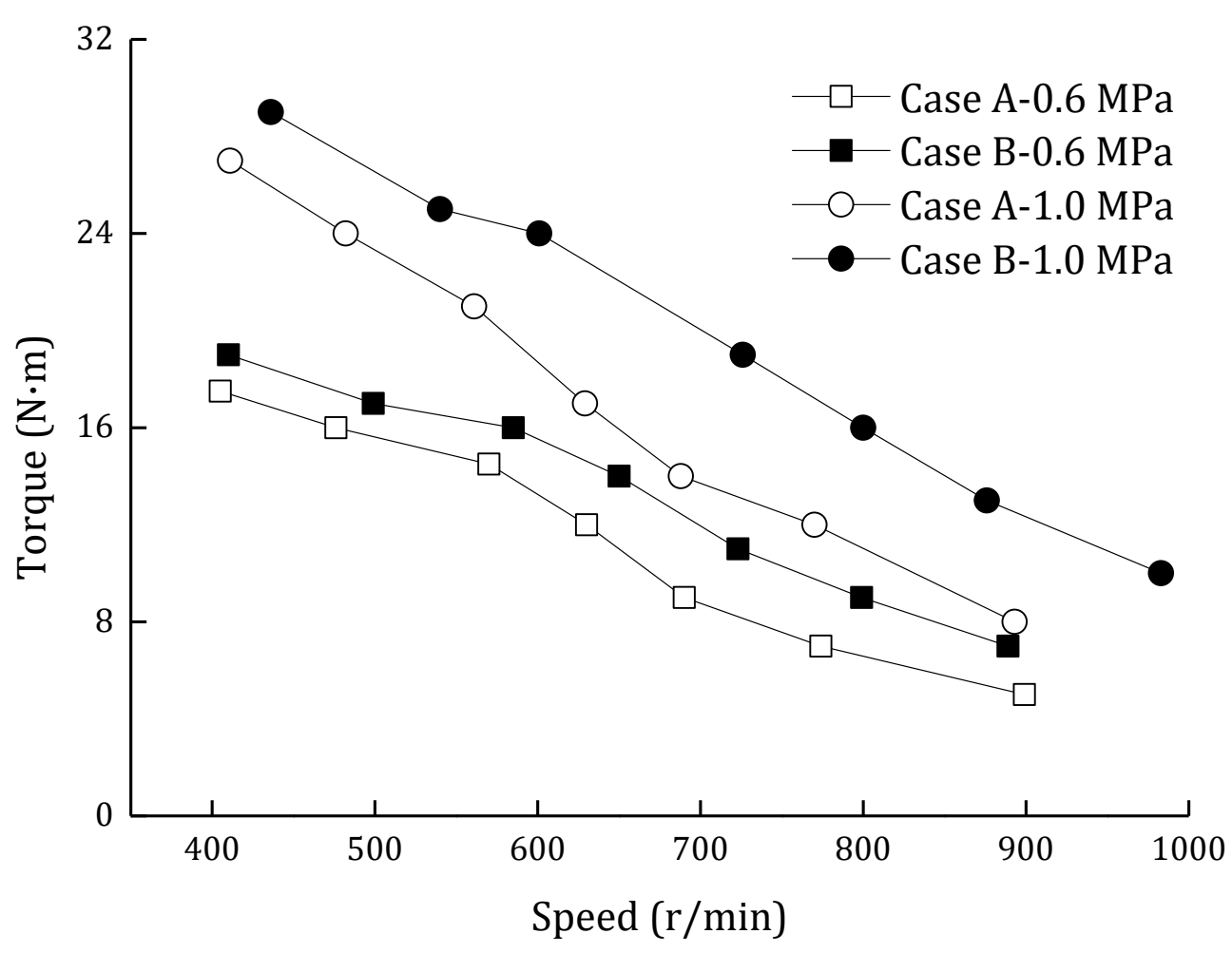

Fig. 8. Pneumatic prototype engine torque vs. engine speed at $p_{\mathrm{i}}=0.6 \mathrm{MPa}, 1.0 \mathrm{MPa}$

It can be noticed that higher wall temperature has positive effect on the performance of the prototype

222 engine. Under the intake pressure $p_{\mathrm{i}}=1.0 \mathrm{MPa}$, the maximum power of the engine is approximately $1.5 \mathrm{~kW}$

223 when the cylinder wall is heated, which is $22 \%$ higher than that of Case A. The maximum torque of the

224 prototype engine is nearly $29 \mathrm{~N} \cdot \mathrm{m}$ when the water is used to heat the cylinder wall, which is increased by

225 approximately 7\% compared to that of Case A. In addition, the torque of the prototype engine reaches $10 \mathrm{~N} \cdot \mathrm{m}$

226 at the engine speed $n=1000 \mathrm{r} / \mathrm{min}$ under Case $\mathrm{B}$, indicating that the engine can slow down the performance

227 deterioration under high speeds with heat supply to compressed air expansion. Similar trends on power and

228 torque of the prototype engine can also be observed when the intake pressure $p_{\mathrm{i}}=0.6 \mathrm{MPa}$. The improvement

229 on the power and torque can be attributed to the optimisation on the expansion of compressed air. When the

230 cylinder wall is heated by the water, the heat transfer between compressed air and cylinder wall is enhanced, 
231 hence the expansion of compressed air is closer to isothermal, leading to an increase in mechanical work 232 output.

Fig. 9 and Fig. 10 illustrate the compressed air flow rate and air consumption of the prototype engine as a 234 function of engine speed $n$. The air consumption of the engine is defined as the mass of compressed air 235 consumed per unit power output, and can be calculated by dividing the compressed air flow rate by the power 236 of the prototype engine. A monotonous increase in both compressed air flow rate and air consumption of the 237 prototype engine can be observed in Fig. 9 and Fig. 10. However, both air mass flow rate and air consumption 238 is lowered under Case B when the engine cylinder wall is heated by the water of $90{ }^{\circ} \mathrm{C}$. When the intake 239 pressure $p_{\mathrm{i}}=1.0 \mathrm{MPa}$, the air consumption is $112 \mathrm{~kg} /(\mathrm{kW} \cdot \mathrm{h})$ at the engine speed $n=980 \mathrm{r} / \mathrm{min}$, while it already 240 exceeds $200 \mathrm{~kg} /(\mathrm{kW} \cdot \mathrm{h})$ at $n=890 \mathrm{r} / \mathrm{min}$ under Case A, when the cylinder wall is not heated. Similar trends on 241 the compressed air flow rate and air consumption of the prototype engine can also be observed when the 242 intake pressure $p_{\mathrm{i}}=0.6 \mathrm{MPa}$. The reduction of compressed air flow is attributed to the increase in cylinder 243 pressure under higher wall temperature due to the enhancement of heat transfer between compressed air and 244 cylinder wall, as shown in Fig. 6. Accordingly, the pressure difference between the cylinder and the intake 245 port is reduced, leading to a lower intake flow rate of the prototype engine. The lower air consumption under 246 Case B is the combined effect of lower compressed air flow rate and higher power output when the cylinder wall is heated by the water. 


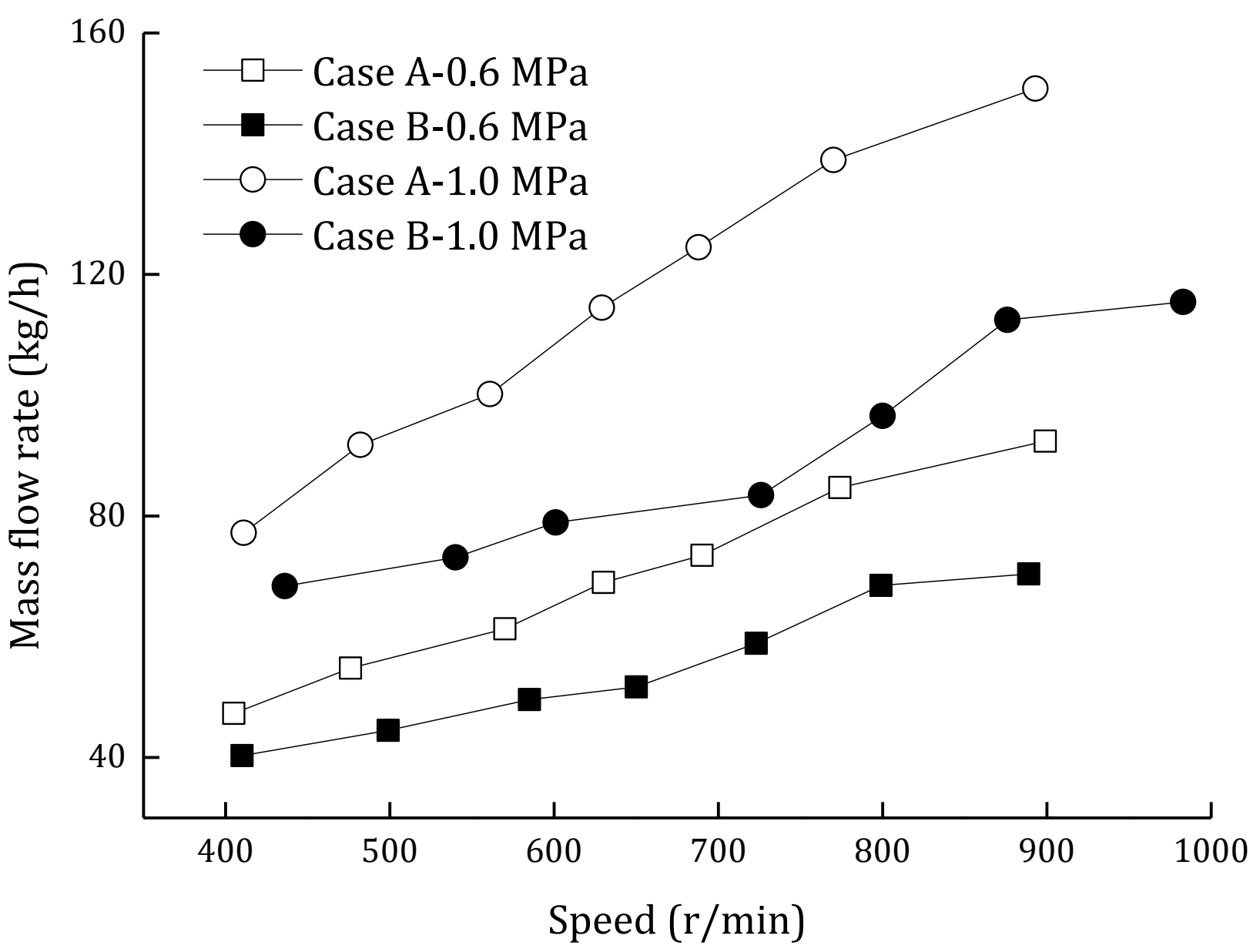

Fig. 9. Compressed air flow rate vs. engine speed at $p_{\mathrm{i}}=0.6 \mathrm{MPa}, 1.0 \mathrm{MPa}$ 


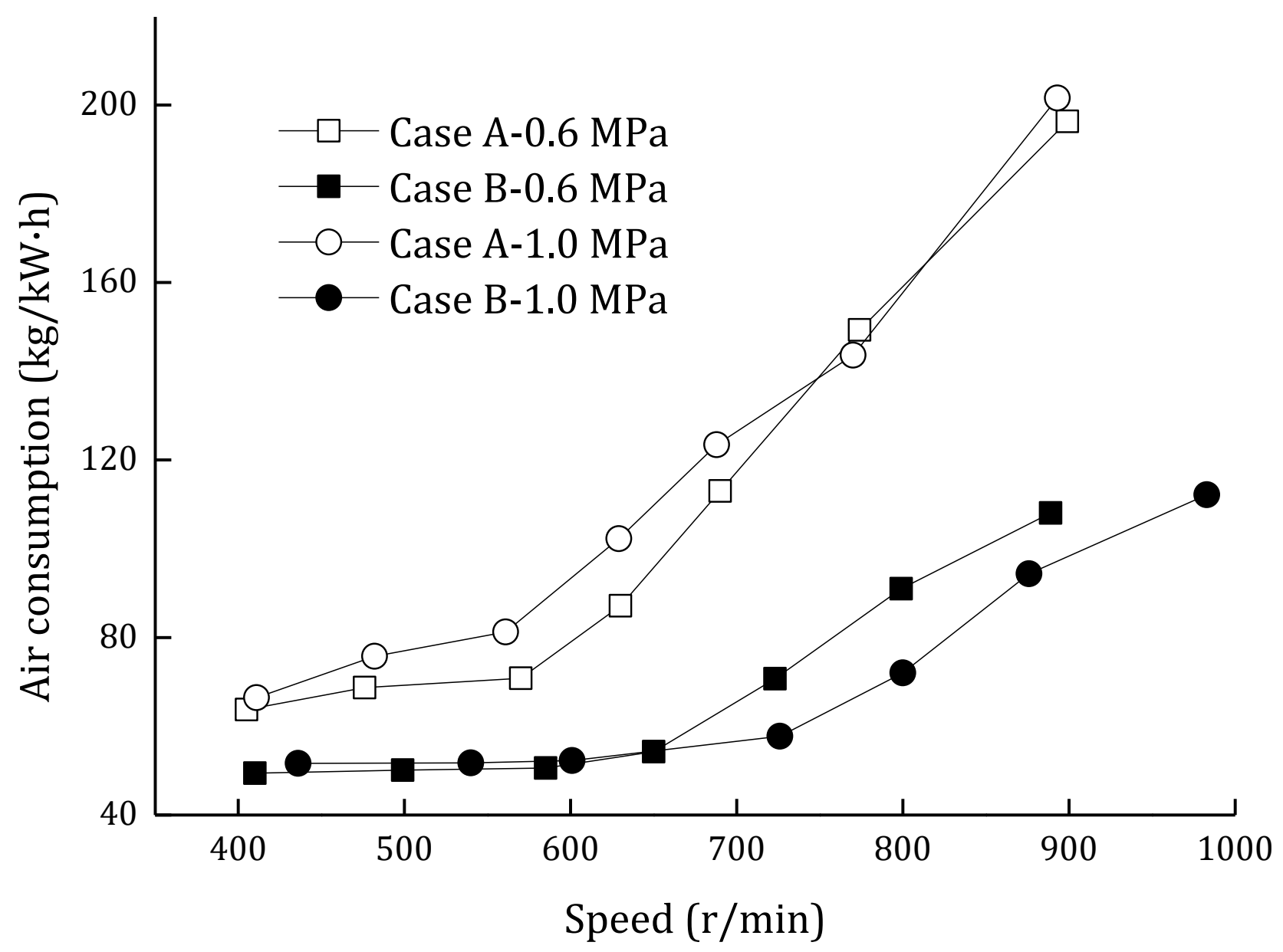

Fig. 10. Air consumption of pneumatic prototype engine vs. engine speed at $p_{\mathrm{i}}=0.6 \mathrm{MPa}, 1.0 \mathrm{MPa}$

Fig. 11 shows the efficiency of pneumatic prototype engine $\eta$ as a function of engine speed $n$ under different conditions. As mentioned above, the legends Case A and Case B refer to the conditions that the engine is operated without or with the heat supply of the water. The efficiency $\eta$ is calculated by dividing the 252 engine power by the total energy of compressed air according to the first law of thermodynamics. As shown in 253 Fig. 11, the efficiency $\eta$ decreases monotonously with engine speed, indicating better efficiency performance 254 can be achieved in lower speeds. Efficiency improvements are observed when the cylinder wall is heated by 255 the water under different intake pressures. The maximum efficiency is increased from approximately $27 \%$ to $25635 \%$ under the intake pressure $p_{\mathrm{i}}=1.0 \mathrm{MPa}$. Similar trend can also be observed when the intake pressure is $p_{\mathrm{i}}=0.6 \mathrm{MPa}$. These improvements can be explained as follows: when the cylinder wall is heated by the water, 


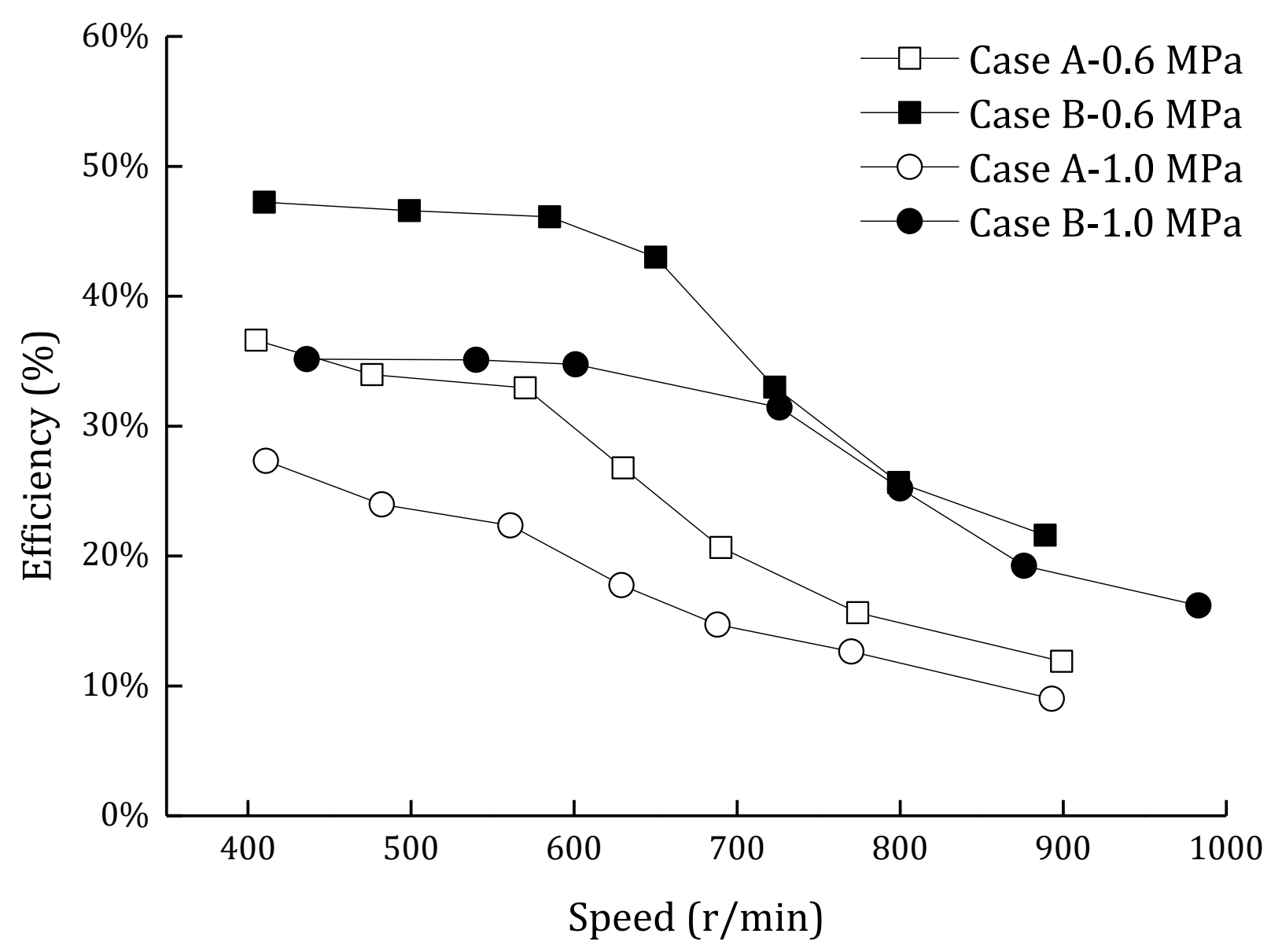

Fig. 11. Pneumatic prototype engine efficiency vs. engine speed at $p_{\mathrm{i}}=0.6 \mathrm{MPa}, 1.0 \mathrm{MPa}$

In summary, it can be concluded that the performance properties of pneumatic prototype engine is optimised when the cylinder wall is heated. Dynamic properties such as power and torque are increased under 263 higher cylinder wall temperature, meanwhile economic property such as air consumption is lowered. In 264 addition, the efficiency performance of the engine is also improved due to the enhancement of heat absorption of compressed air. 


\subsection{Effects of water temperature}

Fig. 12 shows the power of the pneumatic prototype engine as a function of engine speed under different

268 water temperatures $t$ at the inlet of the water jacket. The intake pressure was maintained at $p_{\mathrm{i}}=1.0 \mathrm{MPa}$ during

269 the experiment, and the control of water temperature was realised by the program which enabled on/off switch

270 of the heater. As mentioned above, the legend Case A refers to the conditions that the engine is operated

271 without heat supply, while Case B represents the conditions that the engine works when the cylinder wall is

272 heated by the water. Greater improvement on the power of the pneumatic prototype engine can be noted when

273 the water temperature $t$ is higher. When the water temperature $t=70{ }^{\circ} \mathrm{C}$, the maximum power of the engine is

$2741.4 \mathrm{~kW}$, while it reaches $1.5 \mathrm{~kW}$ when the water temperature is raised to $90{ }^{\circ} \mathrm{C}$. Compared to Case A, the 275 maximum power is improved by $14 \%$ and $22 \%$ under the water temperature $t=70^{\circ} \mathrm{C}$ and $t=90{ }^{\circ} \mathrm{C}$, respectively.

276 The trend can be explained as follows: compressed air absorbs larger amount of heat during expansion when

277 the cylinder wall is heated, leading to an improvement in engine power; when the water temperature is higher,

278 the heat absorption rate of compressed air is further increased due to larger temperature different between the

279 cylinder wall and compressed air; hence greater improvement on the engine power can be observed under

280 higher water temperatures. 


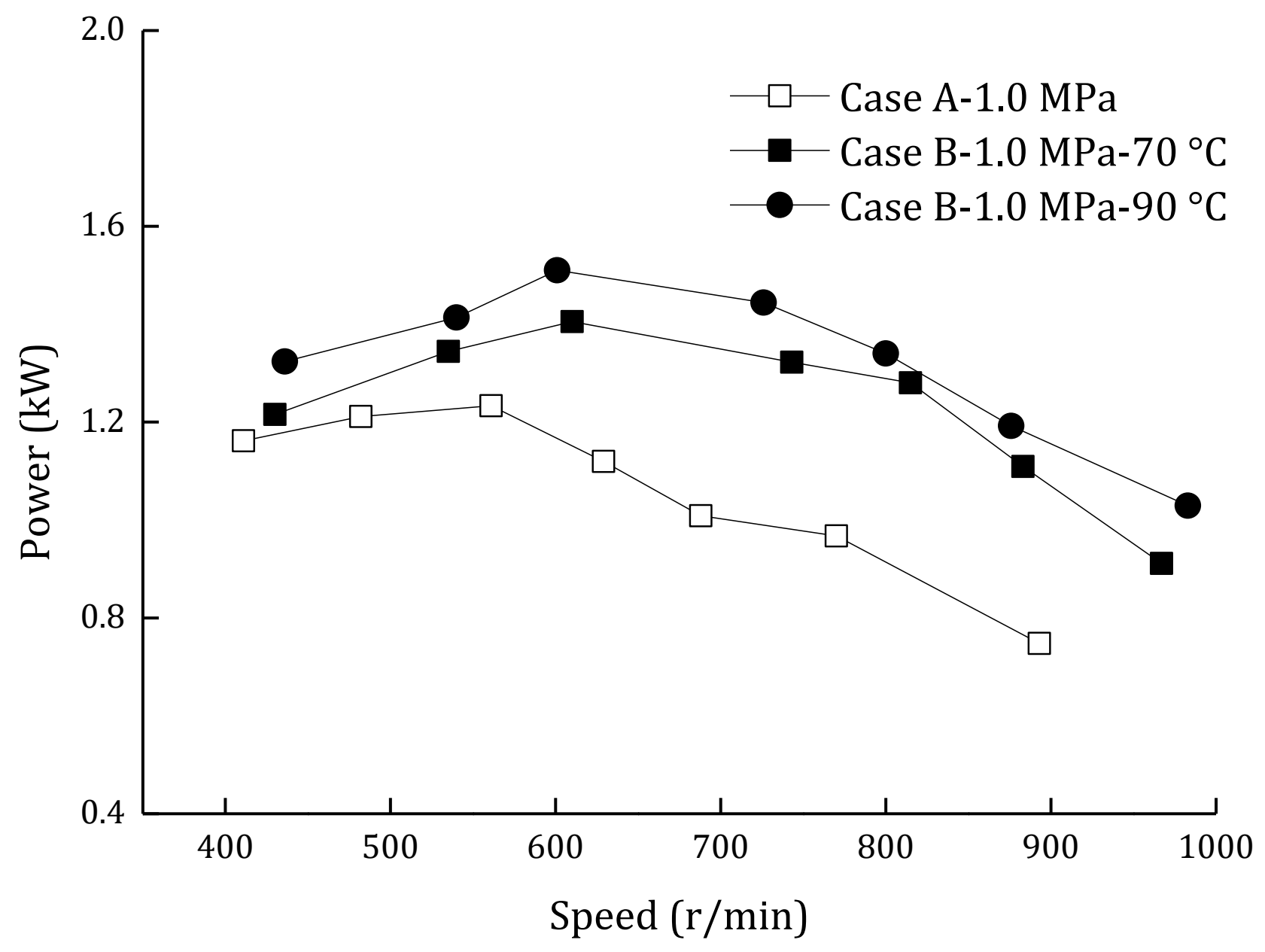

Fig. 12. Pneumatic prototype engine power vs. engine speed at $t=70^{\circ} \mathrm{C}, 90^{\circ} \mathrm{C}$

Fig. 13 and Fig. 14 illustrate the compressed air flow rate and air consumption of pneumatic prototype

engine under different water temperatures $t$, respectively. The intake pressure is maintained at $p_{\mathrm{i}}=1.0 \mathrm{MPa}$

during the test. Larger decrease in both compressed air flow rate and air consumption can be noticed when the

water temperature is raised. When operated without heat supply (Case A), the air consumption of pneumatic

engine exceeds $200 \mathrm{~kg} /(\mathrm{kW} \cdot \mathrm{h})$ at engine speed $n=890 \mathrm{r} / \mathrm{min}$, while it just reaches $140 \mathrm{~kg} /(\mathrm{kW} \cdot \mathrm{h})$ at engine

speed $n=980 \mathrm{r} / \mathrm{min}$ when the cylinder is heated by the water of $70{ }^{\circ} \mathrm{C}$. A further decrease of the air

consumption can be observed when the water temperature is raised to $90{ }^{\circ} \mathrm{C}$. As analysed above, this

phenomenon is the combined effects of lower compressed air flow rate and higher power output under higher 
292 decrease in air consumption can be observed.

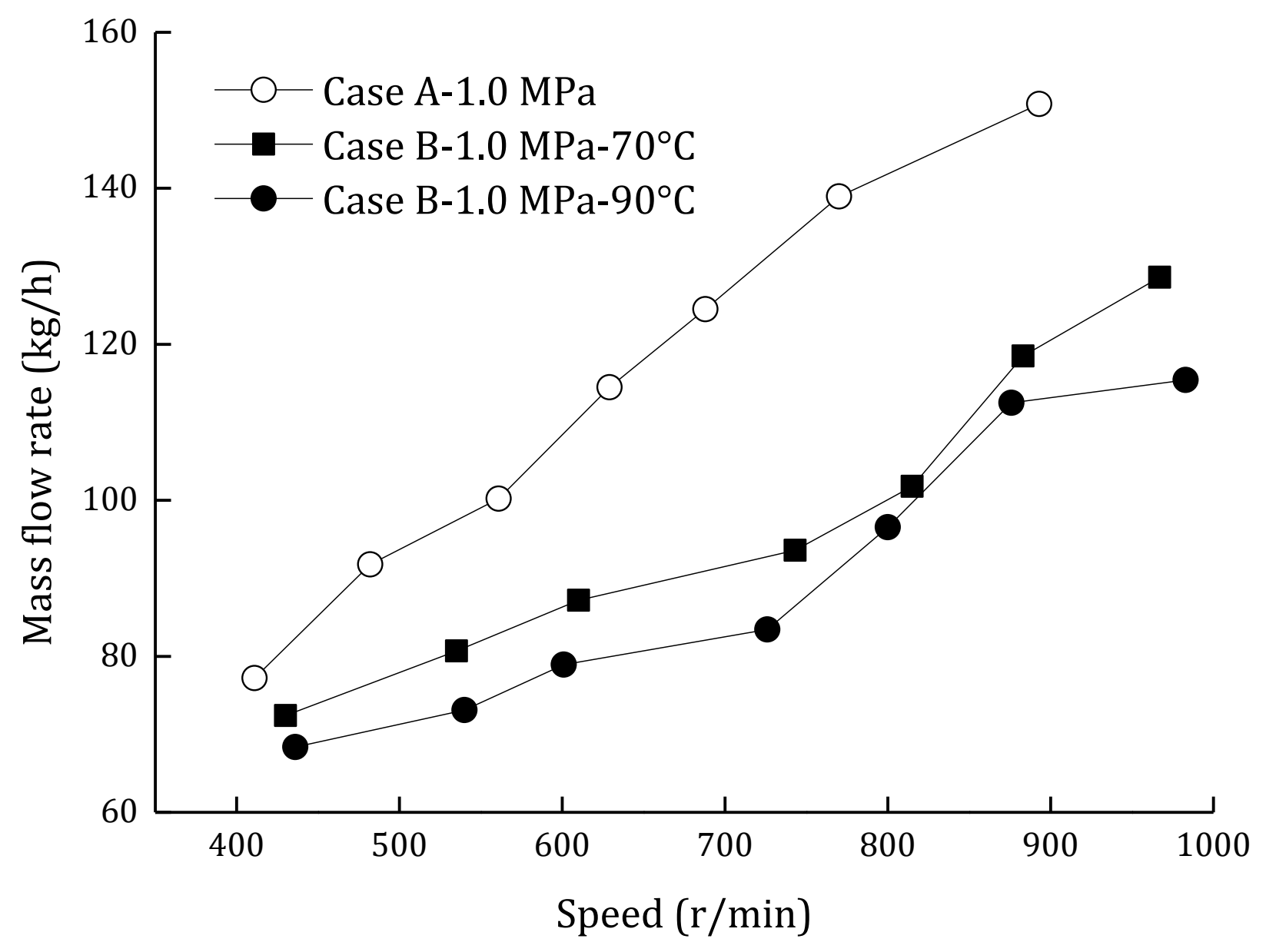

Fig. 13. Compressed air flow rate vs. engine speed at $t=70^{\circ} \mathrm{C}, 90^{\circ} \mathrm{C}$ 


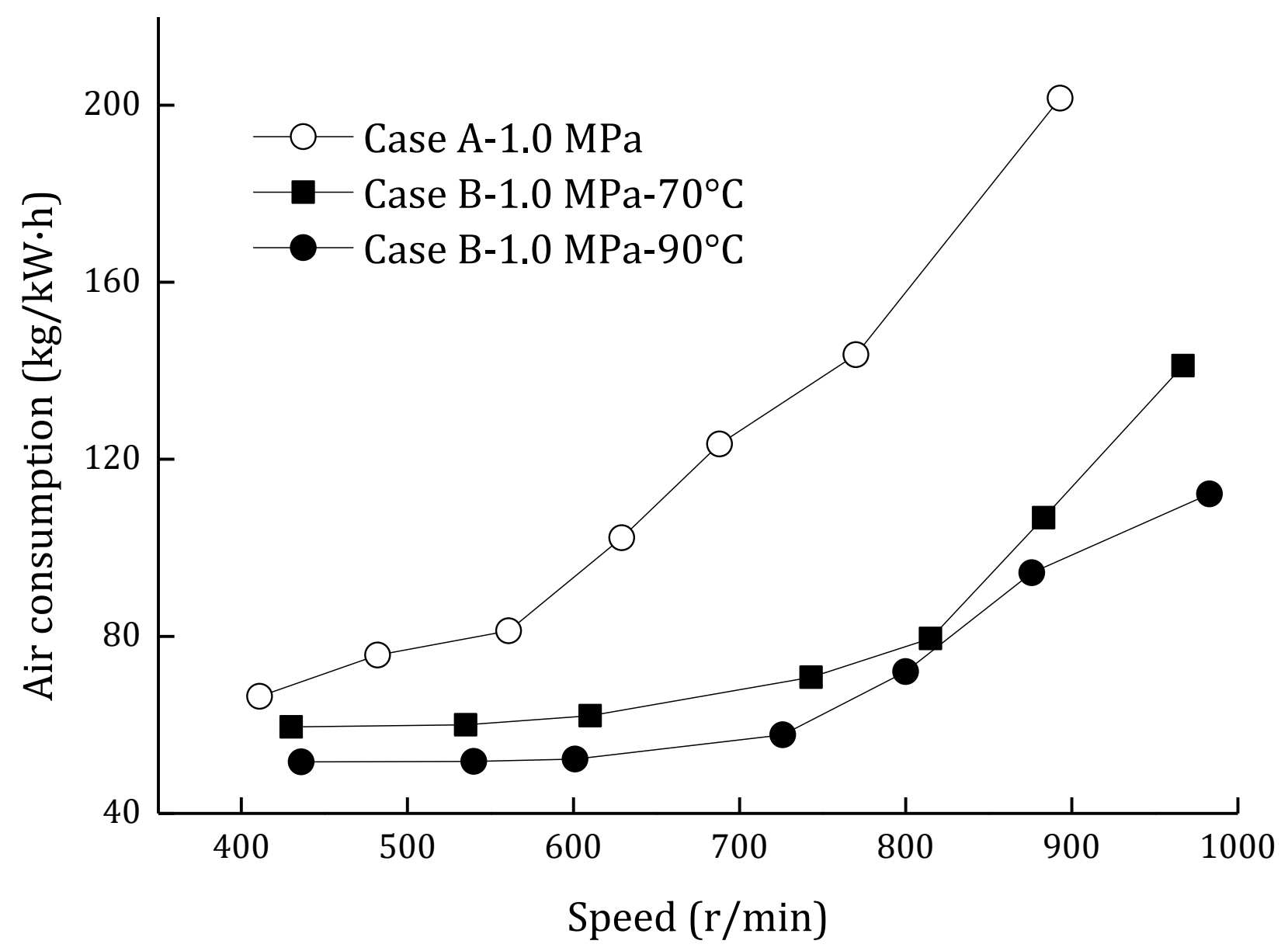

Fig. 14. Air consumption of pneumatic prototype engine vs. engine speed at $t=70{ }^{\circ} \mathrm{C}, 90^{\circ} \mathrm{C}$ mode of HPE, heat source with higher temperature is also available during the operation, such as the exhaust produced in the firing mode.

\section{Conclusions}

This study aims to experimentally investigate the performance of Hybrid Pneumatic Engine (HPE)

single cylinder diesel engine to study the performance of HPE pneumatic mode at steady condition. A heat 
supply system based on cylinder wall heating has been designed, established and used to study the performance of the pneumatic prototype engine with and without heat supply. The conclusions are as follows, during the operation. The power and torque of the engine are increased when the cylinder wall is heated by $90{ }^{\circ} \mathrm{C}$ water. Results indicated the peak cylinder pressure under the heated condition is around $10 \%$ higher than that without heat supply. The maximum power produced from the prototype engine with heat supply $\left(90{ }^{\circ} \mathrm{C}\right)$ is about $1.5 \mathrm{~kW}$, which is $22 \%$ higher than that of the engine without heat. The experimental results also pointed out the torque output from the prototype engine heated by water at $90{ }^{\circ} \mathrm{C}$ is around $29 \mathrm{~N} \cdot \mathrm{m}$, which is $7 \%$ improvement than that without heating supply, under the engine rotational speed at $400 \mathrm{r} / \mathrm{min}$. Moreover, results also shown adding heat supply system can potentially reduce the energy consumption of compressed air supplied from the air storage tank. When the intake pressure is set at $1.0 \mathrm{MPa}$, the air consumption is $112 \mathrm{~kg} /(\mathrm{kW} \cdot \mathrm{h})$ at the engine rotational speed $980 \mathrm{r} / \mathrm{min}$, while it already exceeds $200 \mathrm{~kg} /(\mathrm{kW} \cdot \mathrm{h})$ at $890 \mathrm{r} / \mathrm{min}$ when the cylinder wall is not heated.

The investigation on the overall energy efficiency of the pneumatic prototype engine indicated that under the engine intake pressure at $1 \mathrm{MPa}$, the maximum efficiency of the system can be improved from $27 \%$ to $35 \%$, when the cylinder wall was heated by $90{ }^{\circ} \mathrm{C}$ water. Similar efficiency improvements have also been observed when the engine intake pressure is set at 0.6 MPa under different rotational speed.

The effects of water temperature on the performance of the pneumatic prototype engine were experimentally studied. The supplied water temperature has been set at $70{ }^{\circ} \mathrm{C}$ and $90{ }^{\circ} \mathrm{C}$ under the 
intake pressure set at 1.0 MPa. In total twenty one testing points have been conducted in order to compare the performance of the prototype engine without heating and with two different heat supply temperature. The testing results shown the maximum power output from the prototype engine under water temperature at $70{ }^{\circ} \mathrm{C}$ and $90{ }^{\circ} \mathrm{C}$ can respectively be as high as $1.4 \mathrm{~kW}$ and $1.5 \mathrm{~kW}$, which are about $14 \%$ and $22 \%$ improvement compared with the engine without heat supply.

In conclusion, this paper reports an experimental study, which designed, constructed and used a piston type pneumatic engine using hot water as heat source to prove the feasibility of adding extra heating source to 330 improve the performance of the HPE. The developed system can be potentially be integrated with Internal 331 Combustion Engine (ICE) to recover the wasted kinetic energy during the engine brake process and reuse the wasted heat energy from the ICE such as the coolant and exhaust waste heat in order to effectively improve

the overall energy efficiency of the ICE, reduce the engine emissions and increase the fuel economy.

\section{Acknowledgement}

5151101443 and IE/151256. The first author also would like to acknowledge the support from Funding

Project for Young College Teachers of Shanghai under the grant No. ZZslg16006.

\section{Reference}

340 [1] F. Wasbari, R.A. Bakar, L.M. Gan, M.M. Tahir, A.A. Yusof, A review of compressed-air hybrid technology in 341 vehicle system, Renewable and Sustainable Energy Reviews, 67 (2017) 935-953.

342 [2] Y. Lu, A.P. Roskilly, L. Jiang, L. Chen, X. Yu, Analysis of a $1 \mathrm{~kW}$ organic Rankine cycle using a scroll expander for 343 engine coolant and exhaust heat recovery, Frontiers in Energy, 11 (2017) 527-534.

344 [3] D. Marvania, S. Subudhi, A comprehensive review on compressed air powered engine, Renewable and 345 Sustainable Energy Reviews, 70 (2017) 1119-1130. 
[4] M. Schechter, New Cycles for Automobile Engines, in: Sae Technical Paper, Vol. 1999-01-0623, 1999-01-0623, 1999.

[5] M. Schechter, Regenerative compression braking - A low cost alternative to electric hybrids, in: Sae Technical Paper, Vol. 2000-01-1025, 2000-01-1025, 2000.

[6] P. Higelin, A. Charlet, Thermodynamic Cycles for a New Hybrid Pneumatic-Combustion Engine Concept, Regenerative Braking, (2001).

[7] P. Higelin, A. Charlet, Y. Chamaillard, Thermodynamic Simulation of a Hybrid Pneumatic-Combustion Engine Concept, International Journal of Thermodynamics, 5 (2002).

[8] P. Higelin, I. Vasile, A. Charlet, Y. Chamaillard, Parametric optimization of a new hybrid pneumatic-combustion engine concept, International Journal of Engine Research, 5 (2004) 205-217.

[9] S. Trajkovic, B. Johansson, Simulation of a Pneumatic Hybrid Powertrain with VVT in GT-Power and Comparison with Experimental Data, Sae Technical Paper, (2009).

[10] S. Trajkovic, P. Tunestal, B. Johansson, Vehicle driving cycle simulation of a pneumatic hybrid bus based on experimental engine measurements, Sae Technical Papers, (2010) 2010-2011.

[11] S. Trajkovic, P. Tunestål, B. Johansson, Introductory Study of Variable Valve Actuation for Pneumatic Hybridization, Sae Technical Paper, (2007).

[12] S. Trajkovic, P. Tunestål, B. Johansson, Investigation of Different Valve Geometries and Vavle Timing Strategies and their Effect on Regenerative Efficiency for a Pneumatic Hybrid with Variable Valve Actuation, SAE International Journal of Fuels and Lubricants, 1 (2008) 1206-1223.

[13] S. Trajkovic, P. Tunestål, B. Johansson, A study on compression braking as a means for brake energy recovery for pneumatic hybrid powertrains, International Journal of Powertrains, 2 (2013) 26-51.

[14] C.Y. Lee, H. Zhao, T. Ma, A simple and efficient mild air hybrid engine concept and its performance analysis, Proceedings of the Institution of Mechanical Engineers, Part D: Journal of Automobile Engineering, 227 (2012) 120-136.

[15] C.-Y. Lee, H. Zhao, T. Ma, Pneumatic Regenerative Engine Braking Technology for Buses and Commercial Vehicles, SAE International Journal of Engines, 4 (2011) 2687-2698.

[16] C.-Y. Lee, H. Zhao, T. Ma, Analysis of a novel mild air hybrid engine technology, RegenEBD, for buses and commercial vehicles, International Journal of Engine Research, 13 (2012) 274-286.

[17] H. Zhao, C. Psanis, T. Ma, J. Turner, R. Pearson, Theoretical and experimental studies of air-hybrid engine operation with fully variable valve actuation, International Journal of Engine Research, 12 (2011) 527-548.

[18] C. Donitz, I. Vasile, C.H. Onder, L. Guzzella, Modelling and optimizing two- and four-stroke hybrid pneumatic engines, Proceedings of the Institution of Mechanical Engineers, Part D: Journal of Automobile Engineering, 223 (2009) 255-280.

[19] C. Voser, C. Donitz, G. Ochsner, C. Onder, L. Guzzella, In-cylinder boosting of turbocharged spark-ignited engines. Part 1: Model-based design of the charge valve, Proceedings of the Institution of Mechanical Engineers, Part D: Journal of Automobile Engineering, 226 (2012) 1408-1418.

[20] C. Voser, T. Ott, C. Dönitz, C. Onder, L. Guzzella, In-cylinder boosting of turbocharged spark-ignited engines. Part 2: Control and experimental verification, Proceedings of the Institution of Mechanical Engineers, Part D: Journal of Automobile Engineering, 226 (2012) 1564-1574.

[21] T. Basbous, R. Younes, A. Ilinca, J. Perron, Pneumatic hybridization of a diesel engine using compressed air storage for wind-diesel energy generation, Energy, 38 (2012) 264-275. 
[22] T. Basbous, R. Younes, A. Ilinca, J. Perron, Fuel consumption evaluation of an optimized new hybrid pneumatic-combustion vehicle engine on several driving cycles, International Journal of Engine Research, 13 (2012) 253-273.

[23] T. Basbous, R. Younes, A. Ilinca, J. Perron, A new hybrid pneumatic combustion engine to improve fuel consumption of wind-Diesel power system for non-interconnected areas, Applied Energy, 96 (2012) 459-476. [24] T. Basbous, R. Younes, A. Ilinca, J. Perron, Optimal management of compressed air energy storage in a hybrid wind-pneumatic-diesel system for remote area's power generation, Energy, 84 (2015) 267-278.

[25] H. Ibrahim, R. Younès, T. Basbous, A. Ilinca, M. Dimitrova, Optimization of diesel engine performances for a hybrid wind-diesel system with compressed air energy storage, Energy, 36 (2011) 3079-3091.

[26] H. Ibrahim, R. Younès, A. Ilinca, M. Dimitrova, J. Perron, Study and design of a hybrid wind-diesel-compressed air energy storage system for remote areas, Applied Energy, 87 (2010) 1749-1762.

[27] L. Wang, D. Li, H. Xu, Z. Fan, W. Dou, X. Yu, Research on a pneumatic hybrid engine with regenerative braking and compressed-air-assisted cranking, Proceedings of the Institution of Mechanical Engineers, Part D: Journal of Automobile Engineering, 230 (2016) 406-422.

[28] C.-M. Liu, C.-L. Huang, C.-K. Sung, C.-Y. Huang, Performance analysis of a two-stage expansion air engine, Energy, 115, Part 1 (2016) 140-148.

[29] Y. Shi, J. Sun, M. Cai, Q. Xu, Study on the temperature compensation technology of air-powered engine, Journal of Renewable and Sustainable Energy, 7 (2015) 023112.

[30] X.-H. Nie, X.-L. Yu, Y.-D. Fang, P.-L. Chen, Experiment research on pneumatic diesel hybrid engine based on cooling water energy recovery, Neiranji Gongcheng/Chinese Internal Combustion Engine Engineering, 31 (2010) 58-62.

[31] J.-Q. Hu, X.-L. Yu, X.-H. Nie, P.-L. Chen, Feasibility of parallel air-powered and diesel hybrid engine, Zhejiang Daxue Xuebao (Gongxue Ban)/Journal of Zhejiang University (Engineering Science), 43 (2009) 1632-1637. [32] Y.-D. Fang, D.-F. Li, Y. Yang, X.-L. Yu, Analysis of intake flow loss in pneumatic engine, Neiranji Gongcheng/Chinese Internal Combustion Engine Engineering, 34 (2013) 88-92.

[33] Y. Lu, A.P. Roskilly, X. Yu, K. Tang, L. Jiang, A. Smallbone, L. Chen, Y. Wang, Parametric study for small scale engine coolant and exhaust heat recovery system using different Organic Rankine cycle layouts, Applied Thermal Engineering, 127 (2017) 1252-1266.

[34] Y. Lu, Y. Wang, C. Dong, L. Wang, A.P. Roskilly, Design and assessment on a novel integrated system for power and refrigeration using waste heat from diesel engine, Applied Thermal Engineering, 91 (2015) 591-599. 